\title{
$\mathrm{PH} 100_{\text {debate }}$
}

a debate Repositorios y redes sociales académicas para la transferencia del conocimiento abierto

| coordina Remedios Melero Melero

\section{Los catálogos de museo, una gran oportunidad para el conocimiento abierto... si se abren}

Jorge Sebastián Lozano, Ester Alba Pagán, Cristina Portalés Ricart, Mar Gaitán Salvatella, Arabella León Muñoz | Proyecto SILKNOW ${ }^{1}$, Universitat de València

URL de la contribución <www.iaph.es/revistaph/index.php/revistaph/article/view/4630>

El patrimonio textil es uno de los varios "primos pobres" dentro de la gran familia del patrimonio cultural. Algo especialmente lamentable, pues pocas partes del registro histórico o cultural son tan transversales como los tejidos, tan ricas en información social y connotaciones culturales, técnicas y vitales. Tradicionalmente la seda ha tenido un lugar principal, como tejido de lujo, cuyos productos eran el máximo de las posibilidades materiales y culturales de muchas sociedades. Esto hace también que los objetos de seda sean especialmente abundantes en muchas colecciones históricas; no solo por la indumentaria, sino como parte de objetos funcionales, simbólicos, litúrgicos, mobiliario, etc.

Esas colecciones, a veces en grandes instituciones de rango nacional o global, a veces en pequeñas entidades locales, han sido documentadas de formas muy diversas a lo largo del tiempo. Tras décadas de informatiza-

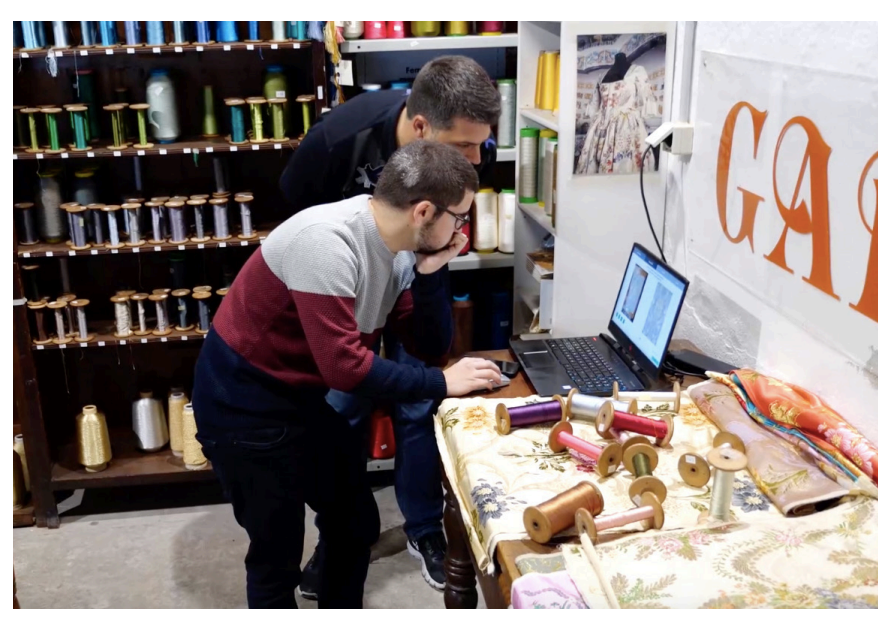

Un equipo interdisciplinar es necesario para abordar con éxito el trabajo en repositorios abiertos, uniendo especialistas en TICs y patrimonio | foto SILKNOW ción en los museos, no son pocos los que cuentan con algún tipo de repositorio digital de sus colecciones. A este respecto, la diversidad de situaciones es abrumadora: desde un sencillo listado en una hoja de cálculo a todo un sistema de gestión de colecciones en la nube.

En el caso del patrimonio textil, esa información ya es abundante en soporte digital, pero normalmente se queda dentro de los muros de las instituciones, al alcance solamente de profesionales y especialistas. La propia naturaleza minoritaria de este patrimonio, antes citada, es causa y consecuencia de esta situación. Fichas de catalogación antiguas, de autoría y autoridad dudosas, poco o nada normalizadas en su estructura y su terminología, según metodologías muy diversas, en idiomas diversos...

Las instituciones museísticas custodian un valioso patrimonio textil; no obstante, es difícil hacerlo atractivo para los canales masivos, pues difícilmente entra en las categorías más habituales en historia del arte, como una autoría asociada a un nombre famoso, una ubicación muy reconocida, o una gran visibilidad pública. En ese sentido, una forma de sacar los tejidos de los expositores y cajones donde son -afortunadamente- preservados es hacerlos máximamente disponibles a través de medios digitales; no ya solo las piezas excepcionales, sino los conjuntos, las series tipológicas, que en estos casos permiten hilar discursos mucho más ricos y significativos. La accesibilidad también ha de ser para el público no especialista o con dificultades de visión o de comprensión intelectual.

Desde SILKNOW (Silk heritage in the Knowledge Society: from punched cards to big data, deep learning 
and visual/tangible simulations) nos hemos propuesto, entre otras cosas, mejorar el acceso a ese patrimonio y la información digital asociada, mediante diversas herramientas. Como todo proyecto reciente del programa Horizonte2020, seguimos una política de acceso abierto a los datos que recopilemos. Provienen de distintas fuentes: fundamentalmente, bases de datos internas facilitadas por museos y colecciones, con los que llegamos a acuerdos; y datos ya en abierto, cosechados mediante API o a través de las sedes web. El resultado, todavía en construcción, será un repositorio donde aunar información de muchas fuentes y hacerlas disponibles a los usuarios mediante herramientas mejoradas: interfaz e interrogación multilingüe, gracias a un tesauro especializado, organizando la información mediante un modelo de datos específico para este tipo de patrimonio, basado en CIDOC-CRM. En esta tarea, apoyamos y proponemos enfoques de acceso abierto a la cultura, concretamente a la catalogación de las colecciones, tal como hacen Europeana o Wikimedia Commons.

Para ello, y dado el tema de este debate, es necesaria una mayor difusión de la cultura de acceso abierto dentro del sector patrimonial y museístico. Las colecciones, los datos en sus catálogos, son la materia prima, no solamente para un proyecto como el nuestro, sino para cualquier desarrollo digital serio en las instituciones del patrimonio. Aunque algunos grandes museos están marcando el camino a seguir (en la estela del Rijksmuseum o el Metropolitan), haciendo libremente disponibles grandes cantidades de datos sobre sus colecciones, a otros les está costando seguir el mismo camino. Nuestro Museo del Prado, puntero en algunos aspectos tecnológicos (con su Archivo Digital o su Modelo Semántico), en este frente no ha avanzado como cabría desear. En otros casos, son instancias gubernamentales las que recogen información de algunas o muchas colecciones: la Red Digital de Colecciones de Museos de España y su portal CERES son un excelente ejemplo a seguir. Su colaboración va a ser clave para SeMap, nuevo proyecto del mismo equipo, recién financiado por el BBVA como proyecto de investigación Fronteras del Conocimiento.
En nuestro caso, al trabajar fundamentalmente con museos medianos o pequeños, estamos encontrando todo el arco de posibles situaciones: desde la cerrazón absoluta a compartir nada, hasta la cesión sin más preguntas, y bastantes matices intermedios. Y eso, dejando claro desde el principio que se trata de un recurso sin ánimo de lucro, tanto ahora como en el futuro; que pedimos datos solamente académicos, no administrativos ni internos del museo; y que hablamos de objetos sobre los que ya no rigen derechos de propiedad intelectual (recogemos datos de tejidos anteriores al siglo XX).

Un repositorio como el que estamos elaborando no suplanta a los museos ni a sus catálogos, sino todo lo contrario, les da más visibilidad. Los usuarios tendrán a su disposición un vínculo con el registro original en el catálogo online de la institución, si existe y tiene un identificador estable. Vamos hacia un escenario en el que coexistan repositorios temáticos (como SILKNOW), junto con grandes agregadores culturales generalistas (como Europeana) y otros nacionales o regionales, definidos por su adscripción a una titularidad pública de mayor o menor amplitud. Otras iniciativas similares proliferarán, proporcionando a las instituciones de patrimonio vías para hacerse más accesibles... si abren la puerta y apuestan seriamente por los datos abiertos.

\section{NOTAS}

1. SILKNOW. Silk heritage in the Knowledge Society: from punched cards to big data, deep learning and visual/tangible simulations ha recibido fondos del programa de investigación e innovación Horizonte2020 de la Unión Europea en virtud del acuerdo 769504. Más información en https://silknow.eu/ 